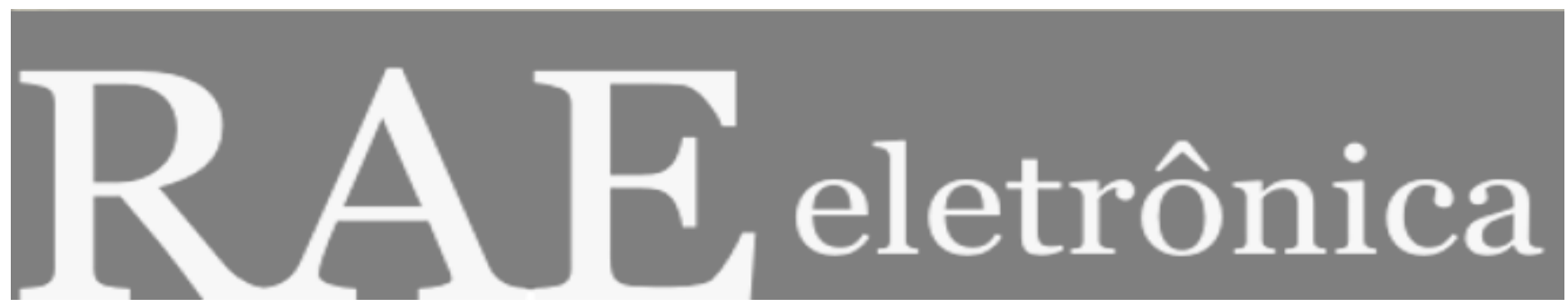

\title{
FINANÇAS CORPORATIVAS NO BRASIL
}

Por:

Ricardo Pereira Câmara Leal

Richard Saito

RAE-eletrônica, v. 2, n. 2, jul-dez/2003.

http:/www.rae.com.br/eletronica/index.cfm?FuseAction=Artigo\&ID=1469\&Secao=FINANÇAS\&Volume=2\&Numer $\mathrm{o}=2 \& A n o=2003$

CCopyright, 2002, RAE-eletrônica. Todos os direitos, inclusive de tradução, são reservados. É permitido citar parte de artigos sem autorização prévia desde que seja identificada a fonte. A reprodução total de artigos é proibida. Os artigos só devem ser usados para uso pessoal e nãocomercial. Em caso de dúvidas, consulte a redação: redacao@rae.com.br.

A RAE-eletrônica é a revista on-line da FGV-EAESP, totalmente aberta e criada com o objetivo de agilizar a veiculação de trabalhos inéditos. Lançada em janeiro de 2002, com perfil acadêmico, é dedicada a professores, pesquisadores e estudantes. Para mais informações consulte o site www.rae.com.br/eletronica.

\section{RAE-eletrônica}

ISSN 1676-5648

C2002 Editora: Fundação Getulio Vargas - Escola de Administração de Empresas de São Paulo.

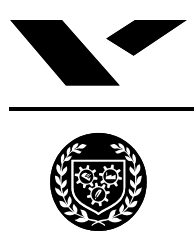




\section{FINANÇAS CORPORATIVAS NO BRASIL}

\section{Ricardo Pereira Câmara Leal}

Doutor, Diretor e Professor de Finanças, Instituto COPPEAD de Administração, UFRJ

E-mail: rleal@coppead.ufrj.br

Endereço: Caixa Postal 68514, Rio de Janeiro, RJ, 21945-970

Interesses de pesquisa: Governança corporativa, gestão de investimentos e finanças internacionais.

\section{Richard Saito}

Ph.D., Professor de Finanças da FGV-EAESP

E-mail: rsaito@fgvsp.br

Endereço: Av. Nove de Julho, 2029, São Paulo, SP, 01313-902.

Interesses de pesquisa: Governança corporativa, finanças corporativas.

\section{RESUMO}

Este artigo revê contribuições acadêmicas sobre finanças corporativas no Brasil relativas à decisão sobre a estrutura de capital, ao controle e a propriedade das empresas, ao processo de emissão de títulos e à governança corporativa. O controle é concentrado no Brasil, mas o valor da empresa cresce desde de que não haja estruturas indiretas de controle e que os controladores tenham uma maior participação nas ações sem direito a voto. O Conselho de Administração é dominado por pessoas relacionadas aos controladores e os acionistas minoritários tendem a não usar mecanismos que aumentem sua representação no Conselho. A escassez de financiamento de longo prazo atinge uma ampla gama de empresas. As firmas geralmente financiam suas atividades através de lucros retidos, emissão de dívida e emissão de ações, nesta ordem. As desvantagens de abrir o capital devem superar as vantagens uma vez que as emissões estão mais raras, têm custo elevado, e tendem a ocorrer com mais freqüência em períodos de euforia no mercado. O valor da empresa está positivamente associado ao pagamento de dividendos e à recompra de ações, mas a influência da tributação sobre a política de dividendos não foi evidenciada.

\section{ABSTRACT}

This article surveys the corporate finance literature in Brazil emphasizing the capital structure decision, ownership and control issues, securities offerings, and corporate governance. Control in Brazil is concentrated, but firm value increases under the absence of indirect control structures and with greater cash flow rights with controlling shareholders. Corporate boards are largely dominated by directors associated with controlling shareholders while minority shareholders tend not to use mechanisms that could allow them to increase their board representation. The lack of long term financing affects a wide range of firms. They usually prefer to finance with retained earnings first, then with debt and lastly with external equity. The disadvantages to go public seem to be greater than the advantages as public offers are becoming rare, the costs of going public are high, and issuance is timed to periods of market euphoria. Equity value is positively related to dividend payments and stock repurchases but the influence of taxation on dividend policy is not clear.

\section{PALAVRAS-CHAVE}

Finanças corporativas; estrutura de capitais; emissão de títulos; governança corporativa; política de dividendos.

\section{KEYWORDS}

Corporate finance, Brazil, capital structure, corporate governance, going public, dividend policy. 


\section{INTRODUÇÃO}

Em nossa experiência como docentes no País freqüentemente verificamos que as dissertações de mestrado e as teses de doutorado e, até mesmo, os artigos produzidos na área de finanças corporativas apresentam uma revisão da literatura internacional mais cuidadosa do que a da literatura nacional. Nosso objetivo é contribuir com uma concisa e limitada revisão da literatura brasileira recente sobre temas selecionados a finanças corporativas de forma que o pesquisador possa usar nosso texto como um ponto de partida de referências existentes na literatura nacional. Não pretendemos realizar uma revisão exaustiva da literatura brasileira, mas uma revisão seletiva, sujeita aos vieses dos autores. É natural que o leitor considere que determinado artigo poderia ter sido incluído e nós reconhecemos esta limitação. Outra delimitação é o foco do artigo. O campo de finanças corporativas é vasto e engloba muitas sub-áreas. Não pretendemos rever todas estas subáreas, mas sim algumas delas, novamente selecionadas segundo os vieses dos autores. Finalmente, nosso objetivo é uma revisão de parte da literatura nacional. Portanto, não incluímos uma revisão da literatura internacional nas mesmas áreas, pois isto seria redundante, dado que há ótimas revisões existentes em língua inglesa, limitando as nossas citações da literatura internacional ao mínimo e a discussão desta literatura em relação à literatura nacional revista também foi minimizada. Além disso, decidimos privilegiar artigos em periódicos nacionais e capítulos de livros dada a sua facilidade de consulta, apesar de incluirmos algumas teses, dissertações e artigos em anais dos principais congressos.

Os temas que escolhemos são aqueles que, segundo nosso julgamento, são os mais freqüentemente pesquisados em finanças corporativas no Brasil, e os que podem ajudar um estudante de pós-graduação a iniciar uma revisão da literatura nacional. Desta forma, iniciamos com a governança corporativa, abordando a estrutura de propriedade e controle no Brasil e questões sobre conflitos de interesse. Prosseguimos com a composição e os determinantes da estrutura de capital no País. Passamos para a emissão de títulos para concluir com a política de dividendos e recompra de ações. A última seção apresenta nossas considerações finais do estágio atual da pesquisa em finanças corporativas no Brasil, e sugere algumas avenidas para futura pesquisa.

\section{GOVERNANÇA CORPORATIVA}

A governança corporativa é o conjunto de regras, práticas e instituições que determinam como os administradores agem no melhor interesse das partes envolvidas na empresa, particularmente os acionistas. Na maioria dos países, e no Brasil, o controle é muito concentrado e os controladores podem monitorar os administradores facilmente. A separação entre administração e controle não é a norma, a administração e o controle freqüentemente são exercidos pelas mesmas pessoas, mesmo nas maiores sociedades de capital aberto. Isto evidencia o conflito entre acionistas controladores e acionistas minoritários no Brasil. O problema central de política nos últimos tempos tem sido o de proteger os acionistas minoritários dos atos predatórios dos acionistas controladores. Nós iniciamos esta seção apresentando alguns trabalhos que descrevem aspectos relacionados à estrutura de controle e de propriedade no Brasil e suas conseqüências sobre o valor das empresas para passarmos a trabalhos que lidam com questões relacionadas ao conselho de administração, que é o principal órgão de representação dos acionistas minoritários na empresa.

\section{Estrutura de controle e propriedade}

Siffert Filho (1998) examina as mudanças no controle societário das empresas brasileiras na década de 1990. O autor estuda as 100 maiores empresas não-financeiras e aponta o crescimento significativo do controle compartilhado por meio de acordos de acionistas. Observa-se também o avanço significativo do controle por empresas estrangeiras e a redução do controle familiar. Siqueira (1998) analisa as causas e conseqüências da concentração da propriedade das empresas 
brasileiras de capital aberto com base em uma amostra de 278 empresas. O autor conclui que o grau de concentração do controle acionário no Brasil sofre influência da regulamentação do mercado, do tamanho da firma e da estrutura de capital.

Procianoy (1994), Procianoy e Comerlato (1994), Valadares e Leal (2000), Valadares (1998, 2002a) e Leal et al. (2002) avaliaram a estrutura de propriedade e controle de companhias de capital aberto no Brasil listadas na Bolsa de Valores de São Paulo. De forma geral, todos os autores concluem que há forte concentração de controle e grande potencial para a expropriação dos acionistas minoritários. Valadares (1998, 2002a), Valadares e Leal (2000), Leal et al. (2000 e 2002) e Carvalhal da Silva (2002) analisaram as estruturas de controle direto e indireto e encontraram um grau de concentração de controle indireto ainda mais alto que o direto. A concentração ocorre principalmente com a violação da regra uma ação-um voto por meio da utilização de ações sem direito a voto e de estruturas indiretas de controle. Entretanto, estes autores sugerem que estruturas indiretas de controle, embora de ampla utilização, parecem não ter como objetivo principal a separação de controle e propriedade uma vez que há concentração tanto nos direitos de voto (ações ordinárias) quanto nos direitos ao fluxo de caixa (ações ordinárias e preferenciais). Talvez seja bom mencionar porque não tem como objeto principal a separação entreo controle e propriedade no caso de holdings (um exemplo estaria bem).

O uso de mecanismos para reduzir o investimento sem perda de controle pode incentivar a expropriação do acionista minoritário. Entretanto, os autores mencionados indicam que os acionistas controladores detêm uma porção significativa do capital total, que inclui ações sem direito a voto, expropriar os minoritários abertamente implicaria a redução do patrimônio dos controladores. Por outro lado, Valadares $(1998,2002$ b) e Nenova (2001) demonstram que o prêmio de controle no Brasil é muito elevado em transações de transferência de controle realizadas de forma privada (e.g. através de block trade na bolsa). Então, ou os benefícios privados de controle, dimensionados pelo prêmio de controle, são de tal magnitude que superam a desvalorização das ações sem direito a voto devido à expropriação dos acionistas minoritários ou não há benefícios privados de controle significativos. A segunda alternativa é muito pouco provável considerando a pouca proteção ao acionista minoritário no Brasil. Srour (2002) apresenta evidência de que melhores práticas de governança corporativa reduzem o risco da empresa e Carvalhal da Silva (2002) sugere que a presença de estruturas indiretas de controle tem efeito negativo sobre o valor da empresa e que quanto maior a participação dos controladores no capital total menor a concentração de controle. É possível que os acionistas controladores detenham uma parcela relevante de ações sem direito a voto por conta da liquidez que oferecem. Por exemplo, Saito (2003) mostra que o valor das ações preferenciais na bolsa em geral é maior do que o valor das ações ordinárias e que o fator mais importante para explicar tal diferença é a maior liquidez das ações preferenciais.

Diante das evidências apresentadas, pode-se concluir que os benefícios privados de controle no Brasil devem ser expressivos. Ainda assim, os controladores detêm ações sem direito a voto. Pode ser que elas constituam parte de sua compensação como executivos da empresa uma vez que podem ser vendidas com facilidade sem alterar a composição do controle da empresa. Melhores práticas de governança e menor separação entre direitos de controle e direitos de propriedade parecem levar a menos risco e mais valor para todos os acionistas.

\section{Gerenciando os conflitos de interesse}

Limitar a esfera de expropriação reforçando os direitos dos minoritários e sua execução são partes essenciais para uma boa prática de governança corporativa. Os benefícios pretendidos são maiores valores de mercado refletidos nos preços das ações, menor custo de agência, implicando menores custos sociais, e maiores oportunidades de investimento. Carvalho (2002) revê diversas medidas recentes tomadas no país e analisa suas possíveis conseqüências. 
Instruções recentes da Comissão de Valores Mobiliários (CVM) e a Lei 10.303/2001 procuram atenuar os conflitos de interesse entre acionistas controladores e minoritários. Por exemplo, a Instrução CVM 361 procura regularizar as situações de recompra e de oferta pública de compra com objetivo de fechamento de capital, enquanto a Lei 10.303/2001 procura amenizar a concentração de controle por meio do limite de emissão de ações preferenciais, concede maior participação de representantes dos acionistas minoritários nos conselhos de administração e no conselho fiscal.

Alterações mais significativas na Lei das Sociedades por Ações em relação ao papel desempenhado pelo Conselho de Administração incluem: a possibilidade de participação de detentores de ações preferenciais na eleição de seus membros ${ }^{1}$ e a votação em separado dos detentores de $15 \%$ das ações ordinárias, que não sejam integrantes do grupo controlador. Ambas sem prejuízo da utilização do voto múltiplo.

É importante destacar que a discussão dos problemas do Conselho de Administração é de natureza distinta daquela observada nos Estados Unidos. Por exemplo, ao contrário do observado nos Estados Unidos por Bhagat e Black (2000), estudo conduzido por Dutra e Saito (2002) demonstra que, nas principais companhias abertas brasileiras, o Conselho de Administração é fartamente dominado por pessoas ligadas ao grupo controlador da companhia, havendo baixa participação de "conselheiros independentes". Estes profissionais, pelo menos em tese, realizariam um trabalho mais efetivo de fiscalização da atividade dos executivos. Dutra e Saito (2000) também examinam se os acionistas minoritários utilizam o "voto múltiplo", mecanismo que poderia facilitar a entrada de acionistas não controladores no Conselho, tendo em vista a utilização de sistemáticas diferenciadas de votação, mas não encontram evidência de que isto aconteça, sugerindo que os minoritários no Brasil não são ativistas ou simplesmente preferem vender suas ações quando insatisfeitos.

A partir destas mudanças, em breve, serão viáveis pesquisas com o objetivo de medir, por exemplo, se a nova lei implicou no aumento da participação de acionistas não-controladores no Conselho de Administração, Fiscal e nas assembléias, com o intuito de usufruir suas novas prerrogativas, e se há maior participação de investidores institucionais locais ou estrangeiros nos processos de deliberação ou votação, levando, ao final, a um custo de capital menor. As práticas de governança no Brasil, decorrentes do nosso ambiente legal, têm conseqüências importantes na forma de financiamento das empresas. A seção seguinte aborda a estrutura de capitais das empresas brasileiras.

\section{ESTRUTURA DE CAPITAIS NO BRASIL}

\section{Composição}

Começamos pela composição da estrutura de capitais das empresas brasileiras que sabidamente não podem contar com um mercado de capitais desenvolvido. Não é surpreendente que o uso de endividamento de longo prazo seja limitado e que a principal fonte de recursos seja a retenção de lucros. Isto limita seriamente a capacidade de crescimento das empresas nacionais. $\mathrm{O}$ endividamento tem sido a forma preferida de financiamento junto ao mercado de capitais e o papel do mercado acionário é limitado ${ }^{2}$.

\footnotetext{
${ }^{1}$ Até a Assembléia Geral Ordinária que irá aprovar as demonstrações financeiras relativas ao exercício de 2005, esta votação dos preferencialistas dar-se-á com base em uma lista tríplice apresentada pelos acionistas controladores.

${ }^{2}$ Veja Sanvicente (2001) e Soares e Procianoy (2000).
} 
Um número limitado de estudos escritos em língua inglesa incluiu o Brasil ${ }^{3}$. Eles mostram que as empresas brasileiras de capital aberto usam mais os lucros retidos e menos o endividamento de longo prazo do que as empresas de outros mercados emergentes. Rodrigues Jr. e Melo (1999) examinaram o fluxo de caixa de empresas de capital aberto entre 1987 e 1996 e concluíram que elas financiavam uma média de $64 \%$ de suas necessidades por meio de lucros retidos, 30\% com endividamento e somente $6 \%$ com emissão de ações ${ }^{4}$. Zonenschain (1998) apresenta resultados similares. Estes autores acreditam que os estudos que os precedem são falhos porque utilizaram dados de balanço patrimonial, que são distorcidos pela inflação e sujeitos a manobras para diminuir a tributação.

Estudos sobre a composição da estrutura de capitais de um grupo abrangente de empresas brasileiras foram feitos por Moreira e Puga (2001), Rocca et al (1998) e Leal (2001). Eles examinaram as decisões de financiamento de uma vasta amostra de firmas industriais brasileiras. Moreira e Puga (2001) usaram a base de dados da Receita Federal para obter informações de 4312 firmas que representavam $53 \%$ da produção industrial em 1997, a maior amostra que conhecemos. Os principais problemas com esta base de dados são a sua natureza tributária e os incentivos que as firmas podem ter para omitir informações. Como nos demais estudos, Moreira e Puga (2001) concluem que as empresas brasileiras dependem mais do financiamento por meio de recursos próprios do que a média de outras nações em desenvolvimento. A média para todas as empresas de capital nacional era de 54\%, com pequenas empresas usando $63 \%$ do financiamento via recursos próprios, e grandes empresas 44\%. As maiores empresas usavam mais financiamento via ações $(26 \%)$ do que as menores $(17 \%)^{5}$. Moreira e Puga (2001) encontram uma maior utilização do endividamento (25\%) do que em estudos anteriores, o que reflete a expansão do mercado de debêntures depois do Plano Real ${ }^{6}$.

Leal (2001) examina três amostras para descrever as escolhas de financiamento de empresas brasileiras. A primeira consiste em dados de 1999 compilados pela Secretaria da Receita Federal. A amostra não inclui instituições financeiras. Empresas muito pequenas que se enquadram no "Simples" também não estão incluídas. A base de dados Economática é a segunda escolha de dados e a amostra consiste em empresas listadas em bolsa em dezembro de 2000 analisadas a partir de dezembro de 1996. Bancos e empresas de seguros foram novamente excluídos. A terceira escolha de dados consiste nas 500 maiores e melhores empresas não-financeiras brasileiras ("Maiores \& Melhores") segundo a revista Exame entre 1996 e 2000 e contém empresas de capital aberto e fechado. Rocca et al. (1998) examinam uma amostra de 644 empresas abertas e fechadas obtida do banco de dados da Austin Asis.

Os resultados de Leal (2001) e Rocca et al. (1998) indicam que um pequeno número de grandes empresas de capital aberto tem acesso aos mercados de crédito e de capitais com despesas de juros relativamente baixas. As empresas menores usam mais dívida de curto prazo do que de longo prazo. As dívidas de curto prazo podem ser mais caras para as empresas menores do que as de longo prazo. O financiamento de longo prazo pode, simplesmente, não estar disponível para estas empresas. A emissão de ações é mínima. O retorno sobre os ativos é muito menor que o custo de financiamento. As empresas de capital fechado têm um nível de endividamento bem menor que o das empresas de capital aberto. O custo do passivo oneroso é menor para as empresas de capital

\footnotetext{
${ }^{3}$ Veja Glen e Pinto (1994), Singh (1994) e Demirgüç-Kunt e Maksimovic (1995) que estudam diversos países com amostras nos anos 80 e início da década de 90.

${ }^{4}$ Soares and Procianoy (2000) sugerem que há mais uso de endividamento depois do Plano Real e que o novo endividamento é predominantemente de curto prazo.

${ }^{5}$ Eid Jr.(1996) apresenta resultados similares por meio de uma pesquisa por questionário feita com uma amostra de empresas de capital aberto e de capital fechado de vários portes.

${ }^{6}$ Pereira (2000) sugere que, apesar de limitado, o uso de endividamento de longo prazo cria valor no Brasil uma vez que o endividamento pode reduzir os conflitos de interesse entre os administradores e os acionistas.
} 
aberto e para empresas maiores. O problema crítico identificado aqui é a escassez de financiamento de passivo de longo prazo para uma ampla gama de empresas.

\section{Determinantes}

Analisaremos agora alguns estudos sobre os determinantes das escolhas da estrutura de capitais feitas por empresas brasileiras. Somente Moreira e Puga (2001) usam uma amostra representativa. Eles mostram que firmas menores, menos intensivas em capital, mais lucrativas e que apresentam maior crescimento usam mais financiamento via recursos próprios do que junto ao mercado de capitais. O financiamento via o mercado de capitais, tanto por endividamento como por ações, é mais importante para empresas maiores, mais intensivas em capital, menos lucrativas e com crescimento mais lento.

Eid Jr. (1996) pesquisou 161 empresas, sendo 59\% sociedades por ações, 35\% sociedades limitadas e $6 \%$ outros tipos de organizações, tais como fundações. Sua amostra consiste em $97,5 \%$ de empresas do setor privado. As empresas parecem preferir o endividamento à emissão de ações para financiar novos projetos e grandes empresas mostram um comportamento oportunista quando se financiam, ao invés de procurar uma estrutura de capital ideal. Por exemplo, $80 \%$ das empresas de capital aberto no estudo consideram suas ações subvalorizadas.

Os estudos que só consideram empresas de capital aberto mostram que elas usam mais endividamento (tanto de curto prazo quanto total) quando elas são menores, têm um crescimento mais lento, têm mais ativos tangíveis e maior participação dos acionistas controladores ${ }^{7}$. Os resultados dos estudos empíricos são consistentes com a teoria do "pecking order" e mostram que as firmas geralmente usam lucros retidos, dívidas e, então, ações, nesta ordem. Terra (2002) também encontra sustentação para o "pecking order" para uma análise conjunta da estrutura de capitais de países latino-americanos numa amostra em que predominam empresas brasileiras.

Nesta seção apresentamos a composição e os determinantes da estrutura de capitais de empresas brasileiras. Na próxima seção revemos a emissão pública de títulos e o custo de capital no Brasil.

\section{EMISSÃO PÚBLICA DE TÍTULOS}

Nesta parte apresentamos as características e os custos das emissões públicas de ações, debêntures e ADR. As vantagens e desvantagens da abertura do capital foram discutidas na literatura nacional por Ness e Pereira (1980), Rocca et al. (1998) e Leal (2000), entre outros. Sem entrar em detalhes, as desvantagens devem superar as vantagens, pois as aberturas de capital por emissão pública de ações vêm se tornando raras. Entre as principais vantagens estão o custo de capital mais baixo e mais acesso a financiamentos. Entre as desvantagens, há a discriminação tributária em relação a empresas fechadas, o custo de se manter uma empresa com o capital aberto e os custos de emissão, tanto diretos quanto indiretos. Os custos para emitir e manter uma empresa como capital aberto são relevantes e serão examinados a seguir.

A comissão de underwriting para a abertura de capital é de $7 \%$ do valor emitido para mais de $90 \%$ das emissões domésticas ou estrangeiras com valor entre US $\$ 20$ e \$80 milhões nos EUA ${ }^{8}$. Jenkinson e Ljungqvist (2001) afirmam que empresas estrangeiras que decidem listar suas ações nos EUA incorrem em um adicional de 1,4\% em despesas e que divulgar a emissão nos EUA custa mais uns $0,4 \%$. Geralmente esta listagem é feita na forma de ADR. No Brasil, Rocca (2001)

\footnotetext{
${ }^{7}$ Veja Perobelli e Famá (2001), Gomes e Leal (2000) e Kayo e Famá (1997).

${ }^{8}$ Veja Chen e Ritter (2000) para as emissões dos EUA e Jenkinson e Ljungqvist (2001) para as emissões de empresas estrangeiras nos EUA.
} 
informa que as comissões de underwriting ficam entre 3\% e 4\% para emissões de ações de maior porte e vão até $10 \%$ para emissões menores. Leal (1998) apresenta um valor médio de 8\% para a comissão no Brasil em uma amostra de aberturas de capital ocorridas entre 1979 e 1992. As comissões para emissão de debêntures são muito mais baixas tanto no país quanto no exterior. Para emissão de títulos de dívida nos EUA, Lee et al. (1996) estimam em 2,09\% os custos médios para debêntures conversíveis com boa classificação de risco e em 3,53\% para as com má classificação de risco. Da mesma forma, as debêntures simples com boa classificação de risco pagam em média $0,94 \%$ do valor total da emissão contra $3,42 \%$ para as emissões mais especulativas.

O deságio inicial das emissões de ações para abertura de capital é elevado no Brasil. Este deságio, conhecido como underpricing na literatura internacional sobre emissões de ações, é a diferença percentual entre o preço de oferta e cotações posteriores no mercado secundário. O preço de mercado mais comum para se medir o deságio é o de fechamento do primeiro dia ${ }^{9}$. Aggarwal et al. (1993) e Leal (1998) analisam o deságio no Brasil para amostras iniciadas após o início de funcionamento da CVM em 1978 até 1992. O preço de fechamento no primeiro dia de negócios em bolsa é em média $74 \%$ maior do que o preço de oferta ou, segundo a mediana, $32 \%$ maior que o preço de oferta. Ness e Pereira (1980) também constatam estes retornos anormais para aberturas de capital anteriores à criação da CVM.

A emissão de ações é um evento relativamente raro no Brasil e muitas vezes realizado em períodos de euforia do mercado, quando os investidores estão particularmente otimistas e parecem pagar preços elevados pelas ações. De fato, Leal (1998) apresenta evidência de timing das aberturas de capital com momentos de valoração acentuada do mercado de ações, particularmente no período após o Plano Cruzado.

Infelizmente, comprar ações de empresas que abriram o capital pelo preço de mercado logo após a emissão parece ser um péssimo negócio. Leal (1998) e Aggarwal et al. (1993) mostram que o investidor que comprou ações de empresas que abriram o capital por meio de emissões de ações pelo preço de fechamento do primeiro dia de negócios perdeu em média cerca de $70 \%$ do valor investido depois de três anos em relação a um investimento no índice Ibovespa. Procianoy e Caselani (1997) sugerem que a destinação de recursos dominante nas emissões de ações varia de ano para ano conforme a conjuntura econômica em que as empresas emitem. Leal (1998) mostra que as empresas que abriram capital em geral eram pouco lucrativas e encontravam-se muito endividadas nos anos anteriores à emissão. Charchat (2000) mostra que a maioria das empresas que abriram capital em 1986 vai à falência, à concordata ou é adquirida poucos anos depois da emissão.

Rocca et al. (1998) apresentam um levantamento dos custos para manter uma empresa com o capital aberto que indica que o custo médio é de US\$ 435 mil e cujo principal gasto é a publicação de informações a preços exorbitantes, com custo médio de US\$ 143 mil. Outros componentes de custo relevantes foram os custos indiretos (US\$ 120 mil) e honorários de auditores externos (US\$ 80 mil). O custo de manutenção elevado foi apontado por Rocca (2001) como a principal desvantagem das empresas de capital aberto.

O custo das cláusulas contratuais pode ser relevante na emissão de debêntures. Filgueira e Leal (2000) comparam as cláusulas das escrituras de debêntures depois do Plano Real com as analisadas por Anderson (1999) antes do Plano Real ${ }^{10}$. Eles constatam que há maior cuidado na elaboração de cláusulas que lidam com os conflitos de interesse uma vez que a inflação deixou de ser o maior problema para o comprador de debêntures. A incidência de cláusulas de atualização

\footnotetext{
${ }^{9}$ Leal e Bocater (1992) revêem o deságio em diversos países que usam diferentes métodos de emissão e concluem que o deságio também é menor quando se usa um procedimento assemelhado a um leilão.

${ }^{10}$ Borges e Lopes (2001) oferecem uma boa revisão das características de debêntures e notas promissórias comerciais enquanto Procianoy e Vaisman (2000) discutem a utilização de debêntures conversíveis no Brasil.
} 
monetária diminuiu enquanto que a ocorrência de cláusulas de juros com spread adicionado a taxas flutuantes tornaram-se mais comuns. A incidência de cláusulas de repactuação programada e de resgate antecipado também diminuiu em relação ao período anterior ao Plano Real. Por outro lado, aumentou a utilização de cláusulas que restringem as ações dos emissores sobre o fluxo de caixa, os ativos e quanto a financiamentos adicionais. Também é mais freqüente o vencimento acelerado quando há mudança na estrutura de propriedade e controle. Posteriormente, Saito et al (2002) confirmaram as hipóteses de Filgueira e Leal (200) para o periodo de 1998-2001, com ênfase para o maior uso de cláusulas para mitigar os conflitos de interesse. Sanvicente (2001) indica que muitas emissões de debêntures são feitas por empresas que não tem ações negociadas em bolsa e que as ações das empresas emissoras de debêntures apresentam valorização no mês em que a emissão é registrada, sugerindo que a limitação das ações dos insiders pelos debenturistas pode ser favorável aos acionistas em geral.

Finalmente, cabe comentar que há evidência de que a emissão de ADR baixa o custo de capital acionário das empresas que o emitem. A maior transparência exigida pelos reguladores dos EUA juntamente com um judiciário mais eficiente pode sinalizar menor risco para os investidores. Entre os trabalhos que analisam o assunto estão os de Rodrigues et al. (1999), Tabak e Lima (2002) e Costa Jr. et al. (1998). Para estimar o custo de capital acionário, Garcia e Bonomo (2001) testam um modelo condicional doméstico de dois fatores para o Brasil e obtêm resultados melhores do que com o CAPM doméstico não condicional tradicional. Schorr et al. (2002) testam um APT doméstico, sem muito sucesso.

Nesta seção verificamos que o uso do mercado de capitais para a emissão de ações vem tornando-se raro e é caro. Os custos diretos e indiretos de emissão podem ser expressivos além do underpricing elevado que revela o baixo valor de mercado das ações. Os períodos de maior atividade no mercado primário brasileiro foram os que coincidiram com valores de mercado elevados, como aconteceu logo após o Plano Cruzado. Entretanto, muitas emissões oportunistas de empresas em má situação financeira foram feitas neste período e a maioria destas empresas já não se encontra mais listada em bolsa. Os resultados encontrados na literatura nacional, tanto para ações quanto para debêntures, sugerem a importância das boas práticas da governança corporativa na avaliação dos títulos emitidos. No caso das ações, o baixo valor de mercado é consistente com um ambiente de pouca proteção legal para o investidor. No caso de debêntures, o uso mais freqüente de cláusulas para mitigar conflitos de interesse revela a preocupação das partes com a governança corporativa. A evidência empírica revista nesta seção apresenta o quadro bem conhecido de elevado custo de capital no Brasil. Na próxima seção será discutido um componente importante da remuneração dos acionistas e do custo de capital das empresas: o pagamento de dividendos.

\section{POLÍTICA DE DIVIDENDOS E RECOMPRA DE AÇÕES}

As recompras de ações servem como uma forma alternativa de distribuir recursos aos acionistas ao invés de dividendos. A maioria dos estudos concorda que as recompras de ações ocorrem em sincronia com os ciclos econômicos enquanto que os dividendos aumentam regularmente com o tempo. Segundo Jagannathan et al. (2000), os dividendos são pagos por empresas com fluxos de caixa operacionais permanentes mais altos, ao passo que as recompras de ações são usadas por empresas com fluxos de caixa não operacionais temporários mais altos. As empresas que recompram também têm fluxos de caixa mais voláteis ${ }^{11}$. Há, portanto, alguma flexibilidade financeira para a escolha entre dividendos e recompras de ações. Entretanto, este não parece o caso do mercado acionário brasileiro.

\footnotetext{
${ }^{11}$ veja Guay e Harford (2000) e Evans et. al. (2001). 
No Brasil, os programas de recompra de ações estão se tornando mais comuns. Entre 1995 e 1999, o número de anúncios de programas de recompra no mercado aberto por empresas brasileiras aumentou $391 \%$ de 11 para 54, e seu valor anunciado aumentou $1437 \%$ de $\mathrm{R} \$ 52,3$ bilhões para $\mathrm{R} \$$ 803,3 bilhões. Os dividendos subiram um pouco menos no mesmo período. A média de rentabilidade de dividendos para empresas não financeiras registradas na Bolsa de São Paulo diminuiu de 3,51\% em 1995 para 2,46\% no primeiro semestre de 1999.

Moreira e Procianoy (2000) confirmam que a hipótese de substituição dos dividendos no caso brasileiro reflete a tributação diferenciada, onde os ganhos de capital são tributados e os dividendos estão isentos de tributação desde 1989 (Lei 7713 de 22/12/88 combinada com Lei 8383 de 30/12/91). Isto representa uma situação inversa dos estudos em paises anglo-saxões. Haveria assim, um incentivo fiscal para a recompra, principalmente como substituto para dividendos extraordinários (Copeland e Weston, 1992). Moreira e Procianoy (2000) examinaram os anúncios de recompra de ações na BOVESPA no período de Maio 1997 a Outubro 1998 e verificaram seu efeito sobre o preço das ações. Os resultados obtidos corroboram o efeito positivo do anúncio de forma progressiva ao longo de aproximadamente 25 dias subseqüentes ao evento.

Saito (2001) analisa a recompra com o objetivo de verificar o impacto da Instrução 299 da Comissão de Valores Mobiliários de fevereiro de 1999 sobre os direitos dos investidores minoritários. Como conseqüência do programa de privatização, a mudança na Lei das S.A. de 1997 diminuiu a proteção aos direitos de acionistas minoritários e a divulgação pública no caso de transferência de controle. Posteriormente, o governo tentou melhorar os direitos dos minoritários aprovando a Instrução 299. Saito argumenta que expropriação ainda pode ocorrer sob a Instrução 299. Por exemplo, o novo acionista controlador pode oferecer um preço mais baixo do que aquele pago para o antigo acionista controlador pela ação dos acionistas minoritários. Além disso, depois que a oferta de recompra de ações termina, o novo acionista controlador pode comprar ações diretamente no mercado a preços ainda mais baixos, devido à liquidez insatisfatória.

O impacto da mudança na legislação sobre a política de dividendos de empresas brasileiras foi analisado por Poli (1993). Poli concluiu que as empresas observadas não buscaram estratégias minimizadoras da carga tributária de seus acionistas. Por outro lado, Procianoy (1996), analisando um período mais extenso que Poli, constatou aumento no índice de pay-out das empresas. Contudo, o autor argumenta que se esperava que os incrementos fossem maiores por conta de razões fiscais.

O impacto do anúncio de pagamento de dividendos sobre o valor da ação foi analisado por Vieira \& Procianoy (1998). Eles concluiram que o retorno anormal encontrado de 16,84\% não é estatiscamente significativo. Os autores pesquisaram também se houve alteração na liqüidez das ações em função do anúncio de bonificação. Entretanto, os resultados encontrados não foram conclusivos. Novis e Saito (2002) analisaram o retorno anormal acumulado nos 90 dias após o anúncio de dividendos para o período 1998-2000, confirmando uma relação positiva entre o rendimento de dividendos e o retorno anormal acumulado das ações no período posterior ao pagamento de dividendos. Os autores confirmaram esta relação quando os eventos foram categorizados segundo o tipo de controlador da empresa, incluindo se foi privatizada ou não.

\section{CONSIDERAÇÕES FINAIS}

Revimos algumas contribuições em finanças corporativas no âmbito do mercado brasileiro. Os trabalhos confirmam a falta de acesso aos mercados de capitais e de crédito e o elevado custo de capital no Brasil. As razões incluem escala por parte das empresas, custos de emissão e questões 
ligadas à governança corporativa. Devido a esta limitação, a geração própria de caixa representa a principal fonte de recursos de nossas empresas.

Este padrão diferenciado, típico em paises emergentes, é, em parte, explicado pela estrutura de controle e propriedade no Brasil. $\mathrm{O}$ uso de ações sem direito a voto e estruturas indiretas de controle explicam, parcialmente, a estrutura de controle e propriedade, favorecendo nitidamente os acionistas controladores.

As empresas procuram formas de minimizar estes custos de agência entre controlador e minoritários, seja na forma de listagem em outras bolsas, seja na forma de sua política de dividendos ou de recompra de ações. Além disso, a CVM e a nova lei das S. A. trouxeram mudanças que atenuam estes custos sociais, como a participação de acionistas minoritários no conselho de administração, além de regras para o fechamento de capital e transferência de controle, minimizando efeitos adversos aos minoritários. Entretanto, os minoritários não parecem utilizar os mecanismos legais disponíveis para aumentar sua representatividade no Conselho de Administração.

Ainda há muito que pesquisar no Brasil. Por exemplo, não são claros os fatores que influenciam na decisão sobre estrutura de capitais. Não sabemos se a adoção de melhores práticas de governança corporativa e de transparência aumenta significativamente o valor das ações, reduzindo os conflitos de interesse e superando o custo destas práticas. Estas e outras questões deverão ser exploradas no futuro.

\section{Artigo recebido em 11.07.2002. Aprovado em 31.03.2003}

\section{REFERÊNCIAS}

AGGARWAL, Reena; LEAL, Ricardo P. C.; Hernández, Leonardo. The aftermarket performance of initial public offerings in Latin America. Financial Management, v. 22, p. 42-53, 1993.

ANDERSON, Christopher W. Financial contracting under extreme uncertainty: an analysis of Brazilian corporate debentures. Journal of Financial Economics, v. 51, p. 45-84, 1999.

BHAGAT, Sanjay; BLACK, Bernard. The non-correlation between board independence and long term firm performance. Journal of Corporation Law, p. 231-274, Winter, 2001.

BORGES, Luiz F. X.; LOPES, Lilia Maria P. M. B. Os valores mobiliários e a captação de empréstimos no mercado financeiro doméstico. Revista do BNDES, v. 8, n. 15, p. 289-308, 2001.

CARVALHAL DA SILVA, A. L. A influência da estrutura de controle e propriedade no valor, estrutura de capital e política de dividendos das empresas brasileiras. Tese (Doutorado em Administração), Instituto Coppead de Administração, Universidade Federal do Rio de Janeiro, 2002.

DE CARVALHO, A. Gledson. Governança corporativa no Brasil em perspectiva. Revista de Administração, v. 37, n. 3, p. 19-32, 2002.

CHARCHAT, Gerson. A triste estória das aberturas de capital no Brasil. In: LEAL, Ricardo P. C.; DA COSTA JR., Newton C. A.; LEMGRUBER, Eduardo F. Finanças Corporativas. São Paulo: Atlas, 2000, p. 141-157. 
CHEN, Hsuan-Chi; RITTER, Jay. The seven percent solution. Journal of Finance, v. 55, n. 3, p. 1105-31, 2000.

CLAESSENS, S.; KLINGEBIEL, D.; LUBRANO, M. Corporate governance reform issues in the Brazilian equity markets. World Bank working paper, 2001.

COPELAND, Thomas E.; WESTON, John F. Financial theory and corporate policy. 3a. edição. Reading: Addison-Wesley Publishing Co., 1992.

DA COSTA JR.; Newton C. A.; LEAL, Ricardo P. C.; LEMME, Celso F.; LAMBRANHO, Paloma P. L. O impacto da dupla negociação: um estudo de eventos de ADRS brasileiros. Revista de Administração, v. 33, n. 4, p. 65-71, out/dez 1998.

DAMODARAN, Aswath. Estimating risk parameters. World Bank working paper, 1999.

DEMIRGÜÇ-KUNT, Asli; MAKSIMOVIC, Vojislav. Capital structure in developing countries: evidence from ten country cases. World Bank working paper, 1995.

DUTRA, Marcos G. L.; SAITO, Richard. Conselhos de Administração: análise de sua composição em um conjunto de companhias abertas brasileiras. Revista de Administração Contemporânea, 6 (2): 9-27, Maio/Agosto, 2002.

EID JR., William. Custo e estrutura de capital: o comportamento das empresas brasileiras. Revista de Administração de Empresas, v. 36, n. 4, p. 51-59, 1996.

EVANS, John P.; EVANS, Robert; GENTRY, James A. The decision to repurchase shares: a cash flow story. Curtin University of Technology Working Paper, 2001.

FENSTERSEIFER, Jaime E.; SAUL, Nestor. Investimentos de capital nas grandes empresas. Revista de Administração, v. 28, n. 3, p. 3-12, 1993.

FILGUEIRA, Antônio; LEAL, Ricardo P. C. Análise de cláusulas de escrituras de debêntures brasileiras após a estabilização econômica. In: LEAL, Ricardo P. C.; DA COSTA JR., Newton C. A.; LEMGRUBER, Eduardo F. Finanças Corporativas, São Paulo: Atlas, 2000, p. $97-115$.

GARCIA, René; BONOMO, Marco. Tests of conditional asset pricing models in the Brazilian stock market. Journal of International Money and Finance, v. 20, p. 71-90, 2001.

GLEN, Jack; PINTO, Brian. Debt or equity? How firms in developing countries choose. Washington: International Finance Corporation, Discussion Paper 22, 1994.

GOMES, Gabriel L.; LEAL, Ricardo P. C. Determinantes da estrutura de capitais das empresas brasileiras com ações negociadas em bolsas de valores. In: LEAL, Ricardo P. C.; DA COSTA JR., Newton C. A.; LEMGRUBER, Eduardo F. Finanças Corporativas, São Paulo: Atlas, 2000, p. 42-57.

GRAY, Wayne; HARFORD, Jarrad. The cash-flow permanence and information content of dividend increases versus repurchases. Journal of Financial Economics, v. 57, n. 3, p. 385415, 2000. 
JAGANNATHAN, Murali; STEPHENS, Clifford P.; WEISBACH, Michael S. Financial flexibility and the choice between dividends and stock repurchases. Journal of Financial Economics, v. 57, n. 3 , p. $355-84,2000$.

JENKINSON, Tim; LJUNGQVIST, Alexander. Going Public - The Theory and Evidence on How Companies Raise Equity Finance. 2a. edição, Oxford: Oxford University Press, 2001.

KAYO, Eduardo K.; FAMÁ, Rubens. Teoria de agência e crescimento: evidências empíricas dos efeitos positivos e negativos do endividamento. Cadernos de Pesquisa em Administração, v. 2, n. 5, p. 1-8, 1997.

LEAL, Ricardo P. C.; BOCATER, Paulo F. Métodos de acesso a ofertas públicas de ações em mercados internacionais. Revista Brasileira de Mercado de Capitais, v. 17, n. 45, p. 7-24, Jul/Dez. 1992.

. Using Accounting Information in Prospectuses to Proxy for the Ex Ante Uncertainty and to Predict the Aftermarket Returns of IPOs. 1998 Annual Meeting of the Business Association of Latin American Studies, Anais ..., abril 1998, p. 1-12.

; CARVALHAL DA SILVA, André L. ; ALOY JR.; Reynaldo V.; NASCIMENTO, Guilherme L. Estrutura de controle e valor de mercado das empresas brasileiras. In: 24o ENANPAD, 2000, Florianópolis. Anais... Florianópolis, 2000 (CD-ROM).

. Três desafios para abrir o capital. Revista da CVM, n. 32, p. 56-61, set. 2000.

. A descriptive analysis of the capital structure of a broad sample of Brazilian firms. World Bank working paper, 2001.

; CARVALHAL DA SILVA, André L. ; VALADARES, Sílvia M. Estrutura de Controle e Propriedade das Companhias Brasileiras de Capital Aberto. Revista de Administração Contemporânea, v. 6, n. 1, p. 7-18, 2002.

LEE, Inmoo; LOCHHEAD, S.; RITTER, Jay; ZHAO, Quanshui. The costs of raising capital. Journal of Financial Research, v. 19, n. 1, p. 59-74, 1996.

MOREIRA, L. F.; PROCIANOY, Jairo L. Recompra de Ações na BOVESPA. Congresso ABAMEC, Anais ..., 2000.

MOREIRA, Maurício M.; PUGA, Fernando P. Como a indústria financia o seu crescimento - uma análise do Brasil pós-real. Revista de Economia Contemporânea, v. 5, p. 35-67, 2001.

NENOVA, T. Control values and changes in corporate law in Brazil. World Bank working paper, 2001.

NESS JR., Walter L.; PEREIRA, Reginaldo F. Mercado primário de ações no Brasil, Mimeo, Rio de Janeiro, IBMEC, 1980.

NOVIS NETO, Jorge; SAITO, Richard. Dividend Yield e Persistência dos Retornos Anormais: Evidência do Brasil. Working Paper, EAESP/Fundação Getúlio Vargas, 2002.

PEREIRA, Sônia B. C. Análise de relação entre valor e alavancagem no mercado brasileiro. In: 24o ENANPAD. (2000: Florianópolis). Anais ... Rio de Janeiro: Associação Nacional de Programas de Pós-Graduação em Administração, 2000 (CD-ROM). 
PEROBELLI, Fernanda F. C.; RUBENS Famá. Fatores determinantes da estrutura de capital: aplicação a empresas de capital aberto no Brasil. Monografia. Universidade de São Paulo, Faculdade de Economia e Administração, 2001.

POLI, Beatriz T. C. A resposta das empresas à modificação tributária brasileira em 1989: dividendos versus ganhos de capital. 105 f. Dissertação (Mestrado em Administração) Programa de Pós-Graduação em Administração, Escola de Administração, Universidade Federal do Rio Grande do Sul, Porto Alegre, 1993.

PROCIANOY, Jairo L.; POLI, Beatriz T. C. A política de dividendos como geradora de economia fiscal e do desenvolvimento do mercado de capitais: uma proposta criativa. Revista de Administração de Empresas, São Paulo, v.33, n.4, p. 6-15, julho/agosto, 1993.

. Dividendos e tributação: o que aconteceu após 1988 - 1989. Revista de Administração, São Paulo, v.31, n.2, p. 7-18, abril/junho, 1996.

; VEISMAN, Eduardo. Debêntures conversíveis em ações e o mercado de capitais brasileiro: revisão e novos questionamentos. In: Leal, Ricardo P. C.; Costa Jr., Newton C. A.; Lemgruber, Eduardo F. Finanças Corporativas, São Paulo: Atlas, 2000, p. 42-57.

; CASELANI, César N. Emissão de ações como fonte de crescimento ou como fonte de redução do risco financeiro: resultados empíricos. Revista de Administração, v.32, n. 3, p. 70-81, 1997.

- O processo sucessório e a abertura de capital nas empresas brasileiras: objetivos conflitantes. Revista de Administração de Empresas, v. 34, n. 4, p. 74-84, 1994.

; COMERLATO, Glória. Proposta de um método para verificação de evidências de transferência de lucro entre empresas similares abertas de um mesmo grupo econômico. In: 18o ENANPAD. Anais... Curitiba, p. 249-264, 1994.

ROCCA, Carlos A.; SILVA, Marcos E.; DE CARVALHO, A. Gledson. Sistema financeiro e a retomada do crescimento econômico. FIPE/Bovespa. 1998.

RODRIGUES, Euchério L.; RAMOS, Patricia B.; BARBOSA, Andreza P. Maior Visibilidade ou integração do mercado de capitais brasileiro? Os efeitos da listagem de ações de empresas brasileiras no mercado norte-americano através do mecanismo de recibos de depósitos de ações. Revista Eletrônica de Administração, v. 5, n. 1, 1999 (disponível em $<$ http://read.adm.ufrgs.br>.

RODRIGUES JR., Waldery; MELO, Giovani M. Padrão de financiamento das empresas privadas no Brasil. Rio de Janeiro: IPEA Documento de Trabalho 653, 1999.

SANVICENTE, Antonio Z. Evolução recente do mercado primário de debêntures. Revista da CVM, p. 63-70, dezembro 2001.

SCHOR, Adriana; BONOMO, Marco Antonio C.; PEREIRA, Pedro Luiz Valls. Arbitrage Pricing Theory (APT) e Variáveis Macroeconômicas - Um Estudo Empírico Sobre o Mercado Acionário Brasileiro, Revista de Economia e Administração, v. 1, n. 1, p. 38-63, 2002.

SAITO, Richard. Determinants of the differential pricing between voting and non-voting shares in Brazil. Brazilian Review of Econometrics, 23(1), May 2003. 
Share Repurchase Rules and Expropriation of Minority Shareholders: Evidence from Brazil. XXV ENANPAD, Campinas, Anais ..., 2001 (em CD-ROM).

; SHENG, Hsia Hua; KOSHIO, Senichiro; DUTRA, Marcos Galileu. Embedded governance in corporate bond indentures: evidence from Brazil, 1998-2001. XXVI ENANPAD, Salvador, Anais ..., 2002 (em CD-ROM).

SIFFERT FILHO, Nelson Governança corporativa: padrões Internacionais e evidências empíricas no Brasil nos anos 90. Revista do BNDES, n. 9, 1998.

SIQUEIRA, Tagore. Concentração da propriedade nas empresas brasileiras de capital aberto. Revista do BNDES, n. 10, 1998.

SOARES, Karina T. C.; PROCIANOY, Jairo L. O perfil de endividamento das empresas negociadas na bolsa de valores de São Paulo após o Plano Real. XXIV ENANPAD, Salvador, Anais ..., 2000 (em CD-ROM).

TERRA, Paulo R. S. An empirical investigation on the determinants of capital structure in Latin America. XXVI ENANPAD, Salvador, Anais ..., 2002 (em CD-ROM).

SROUR, Gabriel. Práticas diferenciadas de governança corporativa: um estudo sobre a conduta e a performance das firmas brasileiras. II Encontro Brasileiro de Finanças, Rio de Janeiro, 22 e 23 de julho de 2002, Anais ..., 2002 (CD-ROM).

TABAK, Benjamim M.; LIMA, Eduardo J. A. The effects of the Brazilian ADRs program on domestic market efficiency. Brasília: Banco Central, Working Paper Series n. 43, 2002.

VALADARES, Sílvia M. Três Ensaios sobre Mercado por Controle no Brasil. Rio de Janeiro: PUC-Rio, Departamento de Economia, Tese de Doutorado, 1998.

. Estrutura de controle e propriedade das empresas brasileiras. In BONOMO, M. org., Finanças Aplicadas ao Brasil, Rio de Janeiro: FGV Editora, p. 275-298, 2002.

. Estimativa de valor de controle no Brasil. In BONOMO, M. org., Finanças Aplicadas ao Brasil, Rio de Janeiro: FGV Editora, p. 299-312, 2002.

; LEAL, Ricardo P. C. Ownership and control structure of Brazilian companies. Revista Abante, v. 3, n. 1, p. 29-56, 2000.

VIEIRA, Kelmara. M.; PROCIANOY, Jairo L.. Investidores reagem a splits e bonificações. ABAMEC, São Paulo, Ano IX, n.81, p.14-17, 2000.

WELCH, Ivo. The equity premium consensus forecast revisited. Cowles Foundation Discussion Paper 1325, Sep., 2001.

ZONENSCHAIN, Claudia N. Estrutura de capital das empresas no Brasil. Revista do BNDES 5(10), p. 63-92, 1998. 